\title{
논문 5
}

[2014-6-BM-005]

\section{$9.9 \mathrm{MW}$ 급 바이오매스 열병합발전 타당성 연구}

최재영*, 설용건**

\section{The Feasibility Analysis of 9.9 MW Biomass Cogeneration System}

Jaiyoung Choi* and Yonggun Shul**

Abstract This study is intended to analyze the appropriate scope for 9.9MW biomass cogeneration, feasibility and sensitivity according to changing market situation. In the study, the heat load is classified into three types to predict heat sales and find out the appropriate scope of thermal business that is operated in CHP $34.42 \mathrm{Gcal} / \mathrm{h}$, PLBwg $70 \mathrm{Gcal} / \mathrm{h}$ of cogeneration. the feasibility is estimated based on internal rate of return (IRR) and net present value(NPV). the sensitivity is analyzed in terms of biomass fuel cost, unit price of heating cost, investment cost, SMP unit price and REC unit price.

Key words

Cogeneration System(열병합발전시스템), Community energy service(집단에너지사업), LNG, Bio(바이오), New renewable energy(신재생에너지), Economic feasibility evaluation(경제성평가), Net present value(순현재가치), Internal rate of return (내부수익률)

(접수일 2014. 6. 17, 수정일 2014. 6. 26, 게재확정일 2014. 6. 26)

* GS파워 영업전략팀 (GS Power, Marketing Strategy Team)

E-mail : chlwo083@hanmail.net Tel : (02)2005-4033 ㅍax : (02)2005-4025

** 연세대학교 화공생명공학과 (Department of Chemical and Biomolecular Engineering, Yonsei University)

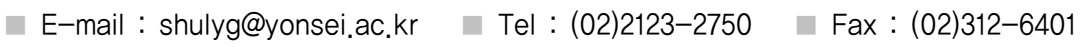

\section{subscrip}

TOE : ton of oil equivalent

$I R R$ : internal rate of return

$N P V$ : net present value

$S M P$ : system marginal price

$C P$ : capacity price

SRF : solid refuse fuel

\section{1. 서 론}

현재 열병합발전을 이용한 집단에너지사업의 대부분은 수 도권 지역에서 사업을 영위하고 있으며 수도권 지역은 연료규 제와 환경규제 등으로 천연가스 위주의 집단에너지사업이 운 영되고 있다. 특히 지역난방 집단에너지사업자의 경우 $93.8 \%$ 를 LNG 연료에 의존하고 있으며 하나의 원별 연료에 과중한 의존은 연료 가격/공급 변동에 따라 사업에 큰 영향을 주고 
있다.

온실가스 감축 및 연료의 다각화를 위해 사업자들은 신재 생에너지 및 미활용에너지를 활용하고 있지만 신재생에너지 를 이용한 집단에너지사업은 몇몇 신재생에너지로 그 범위가 국한되어 있다. 국내에서는 8 개의 재생에너지(태양열, 태양 광발전, 바이오매스, 풍력, 소수력, 지열, 해양에너지, 폐기 물에너지)와 3 개의 신에너지(연료전지, 석탄액화가스화, 수 소에너지)를 신재생에너지로 지정하고 있으며 11 개의 다양한 신재생에너지 중 전기와 열을 동시에 생산하여 열병합발전에 적합한 것은 $\mathrm{SRF}$ 와 $\mathrm{Bio}-\mathrm{SRF}$ 로 한정되어 있다. 그중 $\mathrm{SRF}$ 는 생활폐기물, 폐합성수지류, 폐합성섬유류, 폐고무류, 폐타이 어 등을 사용하여 제조한 고형연료제품이며, Bio-SRF는 폐 지류, 농업폐기물, 폐목재류, 식물성잔재물, 초본류 폐기물 등으로 제조한 고형연료제품 등이 포함되어 있다.

본 연구에서는 에너지 효율이 높은 열병합발전시스템에 바 이오매스 연료를 이용한 사업의 타당성을 분석하여 집단에너 지사업 내 신재생에너지를 사용한 사업에 참고자료를 제공하 고자 한다.

\section{2. 분석기준}

\section{1 분석대상}

열원시설 분석대상은 바이오매스 연료 중 WP(Wood Pellet) 을 연료로 하는 CHP로 전기용량 $9.9 \mathrm{MW}$, 열용량 $30.98 \mathrm{Gcal} / \mathrm{h}$ 으로 설계하였으며, 열공급의 안정성을 위하여 첨두부하보일 러(PLB) $70 \mathrm{Gcal} / \mathrm{h}$ 와 축열조 $52 \mathrm{Gcal} / \mathrm{h}$ 를 추가로 선정하였다 (Table 1, 2).

열수요처 분석대상은 주택/업무/공공으로 구분하였으며, 열수요처 규모는 CHP 열공급 능력 $(30.98 \mathrm{Gcal} / \mathrm{h})$ 을 감안한

Table 1. Analysis of Heat Source Equipment

\begin{tabular}{c|l}
\hline 구분 & \multicolumn{1}{|c}{ Bio 열병합발전 } \\
\hline $\mathrm{CHP}$ & $\begin{array}{l}\text { 전기용량 : } 9.9 \mathrm{MW} \\
\text { 열용량 }: 34.42 \mathrm{Gcal} / \mathrm{h}\end{array}$ \\
\hline $\mathrm{PLBwg}$ & 열용량 $: 70 \mathrm{Gcal} / \mathrm{h}$ \\
\hline 축열조 & 열용량 $: 52 \mathrm{Gcal} / \mathrm{h}$ \\
\hline 방식 & Wood Pellet 전소 발전 \\
\hline
\end{tabular}

연결열부하 $100 \mathrm{Gcal} / \mathrm{h}$ 로 선정하였다. 또한 열수요처 규모에 따라 사업의 타당성을 분석하기 위해 연결열부하 $120 \mathrm{Gcal} / \mathrm{h}$, $140 \mathrm{Gcal} / \mathrm{h}$ 의 열수요처 규모를 추가로 선정하였다(Table 3 ).

열원설비 시공에 따른 투자비는 부지구입비, CHP 건설비, PLB 건설비, 열배관 건설비로 구분하여 산출하였으며 특히 열배관 건설비는 수요처 규모 Case별 시나리오에 따라 산정 하였다(Table 4).

Table 2. Analysis of Fuel for Use

\begin{tabular}{c|l}
\hline 구분 & \multicolumn{1}{|c}{ Bio 열병합발전 } \\
\hline 사용연료 & Wood Pellet \\
\hline 발열량 & HHV $4,300 \mathrm{kcal} / \mathrm{kg}$ \\
\hline 연간투입량 & $88,056 \mathrm{ton} / \mathrm{y}$ \\
\hline 전처리비용 & 연료사용량의 $1.6 \% \times 100,000$ 원/ton \\
\hline 구입비용 & 210,000 원/ton \\
\hline 원산지 & 말레이시아 \\
\hline
\end{tabular}

Table 3. Analysis of Heat Demand by Scenario

\begin{tabular}{c|c|c|c}
\hline CASE & 종별 & $\begin{array}{c}\text { 난방면적 } \\
\left(\mathrm{m}^{2}\right)\end{array}$ & $\begin{array}{c}\text { 연결열부하 } \\
(\mathrm{Gcal} / \mathrm{h})\end{array}$ \\
\hline \multirow{4}{*}{ Case 1 } & 주택 & $1,309,752$ & 86.0 \\
& 업무 & 107,527 & 10.0 \\
\cline { 2 - 4 } & 공공 & 41,667 & 4.0 \\
\cline { 2 - 4 } & Total & $1,458,945$ & 100.0 \\
\hline \multirow{4}{*}{ Case 2 } & 주택 & $1,571,702$ & 103.2 \\
& 업무 & 129,032 & 12.0 \\
\cline { 2 - 4 } & 공공 & 50,000 & 4.8 \\
\cline { 2 - 4 } & Total & $1,750,734$ & 120.0 \\
\hline & 주택 & $1,833,652$ & 120.4 \\
\hline & 업무 & 150,538 & 14.0 \\
\cline { 2 - 4 } & 공공 & 58,333 & 5.6 \\
\cline { 2 - 4 } & Total & $2,042,523$ & 140.0 \\
\hline
\end{tabular}

Table 4. Investment of Heat Source Equipment

\begin{tabular}{c|c|c}
\hline \multicolumn{2}{c|}{ 구분 } & $\begin{array}{c}\text { Bio 열병합발전 } \\
\text { (백만원) }\end{array}$ \\
\hline \multicolumn{2}{c|}{ 부지구입비 } & 26,913 \\
\hline \multicolumn{2}{c|}{ CHP 투자비 } & 44,712 \\
\hline PLBwg 투자비 & 7,845 \\
\hline \multirow{3}{*}{ 열배관 투자비 } & Case 1 & 16,022 \\
& Case 2 & 18,772 \\
\cline { 2 - 3 } & Case 3 & 22,388 \\
\hline
\end{tabular}




\section{2 경제성 분석기준}

사업의 타당성은 현금흐름 할인법인 내부수익률법(IRR)과 순현재가치법(NPV)을 사용하여 분석하였다.

내부수익률법이란 계획사업에 대하여 투자를 했을 경우 장 래의 각 경우마다 예상되는 현금유입과 현금유출을 계산하여 그것의 현재가치를 일치하게 하는 할인율(IRR)을 구하여 경 제성을 평가하는 방법이다.

$$
\begin{aligned}
& \sum_{t=0}^{n} \frac{R_{t}}{(1+r)^{t}}-\sum_{t=0}^{n} \frac{C_{t}}{(1+r)^{t}}=0 \\
& \text { 여기서, Ct }: \text { 현금유출액 } \\
& \mathrm{Rt}: \text { 현급유입액 } \\
& \mathrm{n} \quad: \text { 투자기간 } \\
& \mathrm{t} \quad: \text { 시간 } \\
& \mathrm{r} \quad: \text { 할인율(IRR) }
\end{aligned}
$$

\begin{tabular}{|c|c|}
\hline 항 목 & 적 용 기 준 \\
\hline $\begin{array}{l}\text { 사업분석 } \\
\text { 기간 }\end{array}$ & $\begin{array}{l}\text { 열원건설기간 : 1년차 2년차 } \\
\text { 열배관건설기간 : 1년차 7년차 } \\
\text { 사업기간 : 3년차(최초열공급) 22년차 }\end{array}$ \\
\hline 열원부지 & $19,908 \mathrm{~m}^{2}$ \\
\hline 감가상각 & 상각방법 : 정액법 \\
\hline 자금할인 & 할인율(WACC) : $8.66 \%($ 유사사업 평균치) \\
\hline 보험료 요율 & 직접투자비의 $0.126 \%$ \\
\hline 사용연료 & Wood Pellet \\
\hline 용수비 & 1,768 원/ton \\
\hline 소내동력 & $\begin{array}{l}\text { 발전설비 } 2 \% \\
\mathrm{DH} \text { 설비 } 16.1 \mathrm{~kW} / \mathrm{Gcal}\end{array}$ \\
\hline 경상 인건비 & $\begin{array}{l}\text { 운영인력 : } 5 \text { 명, 인건비 } 5000 \text { 만원/인 } \\
\text { 재경비 : 인건비의 } 40 \%\end{array}$ \\
\hline 수선 유지비 & $\begin{array}{l}\text { 열원설비(토지 및 열배관 제외) } X \text { 수선유지비율 } \\
\text { * 열원설비연도별 수선유지비율 } \\
\text { 1년(0.3\%), 2년(0.6\%), 3년(0.9\%), 4년(1.2\%), 5년(1.4\%), } \\
\text { 6년(1.6\%), 7년(1.8\%), 8년(2.0\%), 9년(2.2\%), 10년이후 } \\
\text { (2.2\%) } \\
\text { 열배관 : 열배관 취득가액의 0.7\% 적용 }\end{array}$ \\
\hline 기타 & $\begin{array}{l}\text { 제세 : } 0.1 \%(\text { 직접투자비+부지구입비) } \\
\text { 법인세 : } 24.2 \% \\
\text { 물가상승률 : } 3 \%\end{array}$ \\
\hline
\end{tabular}

식 (1)을 만족시키는 $r$ 의 값을 투자사업의 내부수익률이라

\section{Table 5. Standard of Economic Analysis}

하며 기업에서 바라고 있는 최저수익률과 비교하여, 내부수 익률이 높으면 경제성이 있다고 판단하는 방법이다.

순현재가치법이란 계획사업에 대하여 투자로부터 기대되 는 미래의 현금유입액에서 유출액을 차감하고 순현금 흐름액 을 자본비용으로 할인하여, 식 (2)와 같이 순현재가치(NPV) 를 산출하고 산출된 순현재가치가 0 보다 크면 경제성이 있다 고 평가하는 방법이다.

$$
N P V=\sum_{t=0}^{n} \frac{R_{t}}{(1+k)^{t}}-\sum_{t=0}^{n} \frac{C_{t}}{(1+k)^{t}}
$$

여기서, $\mathrm{Ct}$ : 현금유출액

Rt : 현급유입액

$\mathrm{n}$ : 투자기간

$\mathrm{K}$ : 자본비용 또는 자본의 기회비용

$t$ : 시간

상호배타적인 투자안의 경우 NPV 값이 보다 큰 투자안을 채택한다. 투자안들이 상호 독립적이고 자본의 조달에 한계가 있는 경우에는 투자규모를 고려하여 상대적으로 NPV 값이 큰 것부터 순서대로, 자본허용한도까지 투자안을 선택한다.

$\mathrm{CHP}$ 건설기간은 2 년(1년차 2 년차), 열배관 건설의 7 년(1 년차 7년차)으로 설정하였으며, 경제성 분석기간은 최초 열 공급 시기를 기준으로 20 년(3년차 22년차)을 분석하였다.

감가상각방법은 정액법으로 20 년을 적용하였으며, 물가상 승률은 연 $3 \%$ 로 가정하였다. 할인율(WACC)의 경우 유사사 업 평균치인 8.66\%을 적용하였다(Table 5).

\section{3 열수요 분석기준}

난방 및 냉방 연결열부하 및 최대열부하는 집단에너지 사 업계획서 작성기준(지식경제부고시, 제2012-180호)을 기준 으로 산정하였으며, 최대부하 산출시 적용한 부하율은 집단 에너지시설의 최적화 방안 연구(에너지경제연구원, 2010)에 서 조사한 집단에너지사업자의 주택/업무/공공 냉난방 실적 최대부하율 $51.8 \%$ 를 적용하여 산정하였다.

연도별 열부하 분포는 열수요처의 입주에 따라 분배하였으 며, 주택의 경우 포화수요기간을 5 년을 기준으로 연도별 입 주율은 $30 \%, 65 \%, 85 \%, 95 \%, 100 \%$ 로 고려하였다. 공공은 
주택 입주시기와 동일하게 적용, 업무는 주택 입주시기의 2 배로 하여 매년 균등 부하분포를 적용하였다.

열사용량은 외기온도에 따라 사용자가 사용하는 열사용량 을 시간대별( 8,760 시간)로 예측하여 산출하였으며, 이때 적 용한 외기온도는 기상청의 서울지역 3개년(2010년 2012) 8,760 시간 기온자료를 적용하였다(Fig. 1).

\section{4 생산계획 분석기준}

전력시장가격은 전력거래소의 $\mathrm{SMP}$ 를 결정하는 원료를 적

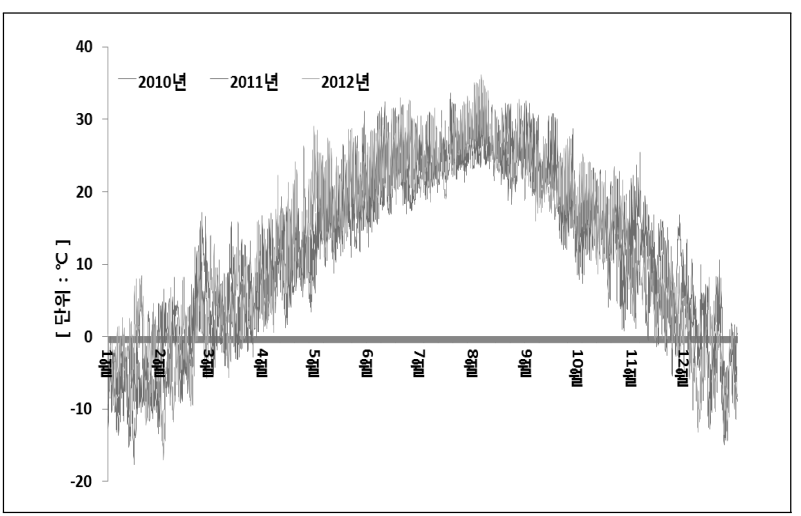

Fig. 1 Temperature Data of Korea Meteorological Administration in Seoul from 2010 to 2012

Table 6. The Ratio for Determining SMP (unit : \%)

\begin{tabular}{c|c|c|c|c|c|c|c}
\hline 구분 & 2006 & 2007 & 2008 & 2009 & 2010 & 2011 & 2012 \\
\hline LNG & 65.2 & 70.6 & 78.0 & 71.7 & 79.6 & 87.0 & 88.2 \\
\hline 유류 & 18.1 & 19.4 & 11.9 & 11.4 & 13.5 & 7.2 & 11.8 \\
\hline 유연탄 & 7.9 & 4.5 & 6.8 & 11.9 & 3.4 & 3.0 & 0.0 \\
\hline 무연탄 & 8.8 & 5.5 & 3.3 & 5.0 & 3.5 & 2.8 & 0.0 \\
\hline 원자력 & 0.0 & 0.0 & 0.0 & 0.0 & 0.0 & 0.0 & 0.0 \\
\hline
\end{tabular}

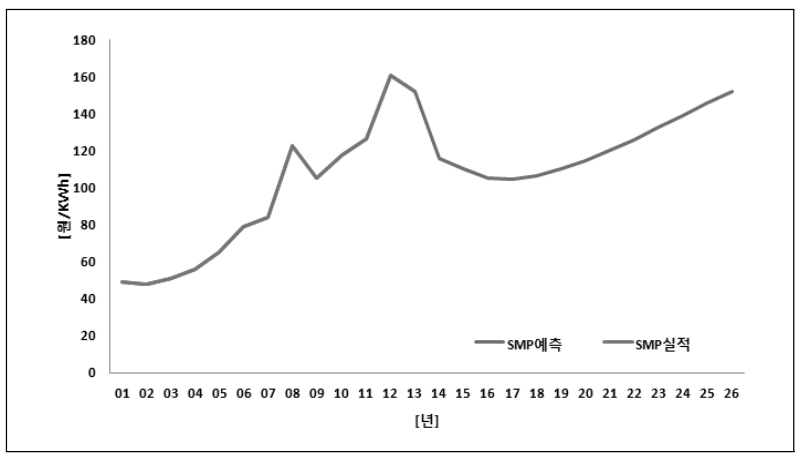

Fig. 2 Performance and Prospects for SMP
용(Table 6), SMP를 결정하는 과거 원료별 가격과 과거 SMP 를 회귀분석 한 후, 향후 원료별 예측가격에 동 회귀식을 적용 하여 예측하였다. 이때 과거 원료별 단가는 $\mathrm{BP}$ 와 EIA의 실적 자료를, 향후 원료별 예측단가는 EIA의 2014 Annual Energy Outlook 가격예측 시나리오를 적용하였다(Fig. 2).

용량요금은 2013년 단위용량가격(7.46원/kwh)을 적용하 였고, 열생산시설에서 열수요처 까지의열 손실률은 $4 \%$ 를 적 용하였다.

\section{3. 분석결과}

\section{1 열수요 분석결과}

난방 열수요 분석결과 연결열부하 $100 \mathrm{Gcal} / \mathrm{h}$ 경우 포화년 도 열판매량은 $138,246 \mathrm{Gcal} / \mathrm{y}$, 연결열부하 $120 \mathrm{Gcal} / \mathrm{h}$ 경우 열판매량은 $165,893 \mathrm{Gcal} / \mathrm{y}$, 연결열부하 $140 \mathrm{Gcal} / \mathrm{h}$ 경우 열판 매량은 $193,540 \mathrm{Gcal} / \mathrm{y}$ 로 분석되었고, 냉방의 경우 연결열부 하 $12 \mathrm{Gcal} / \mathrm{h}$ 경우 포화년도(12년차) 열판매량은 $2,788 \mathrm{Gcal} / \mathrm{y}$, 연결열부하 $14 \mathrm{Gcal} / \mathrm{h}$ 경우 열판매량은 $3,346 \mathrm{Gcal} / \mathrm{y}$, 연결열 부하 $17 \mathrm{Gcal} / \mathrm{h}$ 경우 열판매량은 $3,904 \mathrm{Gcal} / \mathrm{y}$ 로 분석되었다 (Table 7).

열도별 열수요 분석결과 사업 3 년차에 열공급이 시작되어 사업 12 년차에 열수요 개발이 완료되고 사업 12 년차 이후 열

Table 7. Analysis Result of Heat Demand in Saturation Period

\begin{tabular}{c|c|c|c}
\hline \multirow{2}{*}{ 구분 } & 종별 & $\begin{array}{c}\text { 난방 열판매량 } \\
\text { (Gcal/y) }\end{array}$ & $\begin{array}{c}\text { 냉방 열판매량 } \\
\text { (Gcal/y) }\end{array}$ \\
\hline \multirow{4}{*}{$\begin{array}{c}\text { Case } \\
1\end{array}$} & 주택 & 121,869 & - \\
\cline { 1 - 3 } & 업무 & 12,489 & 2,154 \\
\cline { 1 - 4 } & 공공 & 3,888 & 634 \\
\cline { 2 - 4 } Case & Total & 138,246 & 2,788 \\
\hline \multirow{4}{*}{2} & 주택 & 146,241 & - \\
& 업무 & 14,986 & 2,585 \\
\cline { 2 - 4 } & 공공 & 4,666 & 761 \\
\cline { 2 - 4 } Case & Total & 165,893 & 3,346 \\
\hline \multirow{3}{*}{3} & 주택 & 170,613 & - \\
\cline { 2 - 4 } & 업무 & 17,483 & 3,016 \\
\cline { 2 - 4 } & 공공 & 5,444 & 888 \\
\cline { 2 - 4 } & Total & 193,540 & 3,904 \\
\hline
\end{tabular}




\section{노눈 5}

Table 8. Case 1 Analysis Result of Heat Demand by Year

\begin{tabular}{c|c|c|c}
\hline \multirow{2}{*}{ 기간 } & \multicolumn{3}{|c}{ Case 1 } \\
\cline { 2 - 4 } & $\begin{array}{c}\text { 연결열부하 } \\
\text { (Mcal/h) }\end{array}$ & $\begin{array}{c}\text { 최대열부하 } \\
\text { (Mcal/h) }\end{array}$ & $\begin{array}{c}\text { 냉난방 열판매량 } \\
\text { (Gcal/y) }\end{array}$ \\
\hline 3년차 & 28.0 & 14.5 & 39,382 \\
\hline 4년차 & 60.5 & 31.3 & 85,083 \\
\hline 5년차 & 79.5 & 41.2 & 111,825 \\
\hline 6년차 & 89.5 & 46.4 & 125,929 \\
\hline 7년차 & 95.0 & 49.2 & 133,713 \\
\hline 8년차 & 96.0 & 49.7 & 135,177 \\
\hline 9년차 & 97.0 & 50.2 & 136,641 \\
\hline 10년차 & 98.0 & 50.8 & 138,105 \\
\hline 11년차 & 99.0 & 51.3 & 139,570 \\
\hline 12년차 & 100.0 & 51.8 & 141,034 \\
\hline & & &
\end{tabular}

Table 9. Case 2 Analysis Result of Heat Demand by Year

\begin{tabular}{c|c|c|c}
\hline \multirow{2}{*}{ 기간 } & \multicolumn{3}{|c}{ Case 2 } \\
\cline { 2 - 4 } & $\begin{array}{c}\text { 연결열부하 } \\
\text { (Mcal/h) }\end{array}$ & $\begin{array}{c}\text { 최대열부하 } \\
\text { (Mcal/h) }\end{array}$ & $\begin{array}{c}\text { 냉난방 열판매량 } \\
\text { (Gcal/y) }\end{array}$ \\
\hline 3년차 & 33.6 & 17.4 & 47,257 \\
\hline 4년차 & 72.6 & 37.6 & 102,098 \\
\hline 5년차 & 95.4 & 49.4 & 134,189 \\
\hline 6년차 & 107.4 & 55.6 & 151,113 \\
\hline 7년차 & 114.0 & 59.1 & 160,453 \\
\hline 8년차 & 115.2 & 59.7 & 162,210 \\
\hline 9년차 & 116.4 & 60.3 & 163,967 \\
\hline 10년차 & 117.6 & 60.9 & 165,725 \\
\hline 11년차 & 118.8 & 61.5 & 167,482 \\
\hline 12년차 & 120.0 & 62.2 & 169,239 \\
\hline & & &
\end{tabular}

Table 10. Case 3 Analysis Result of Heat Demand by Year

\begin{tabular}{c|c|c|c}
\hline \multirow{2}{*}{ 기간 } & \multicolumn{3}{|c}{ Case 3 } \\
\cline { 2 - 4 } & $\begin{array}{c}\text { 연결열부하 } \\
\text { (Mcal/h) }\end{array}$ & $\begin{array}{c}\text { 최대열부하 } \\
\text { (Mcal/h) }\end{array}$ & $\begin{array}{c}\text { 냉난방 열판매량 } \\
\text { (Gcal/y) }\end{array}$ \\
\hline 3년차 & 39.2 & 20.3 & 55,133 \\
\hline 4년차 & 84.7 & 43.9 & 119,114 \\
\hline 5년차 & 111.3 & 57.7 & 156,553 \\
\hline 6년차 & 125.3 & 64.9 & 176,297 \\
\hline 7년차 & 133.0 & 68.9 & 187,194 \\
\hline 8년차 & 134.4 & 69.6 & 189,244 \\
\hline 9년차 & 135.8 & 70.3 & 191,294 \\
\hline 10년차 & 137.2 & 71.1 & 193,344 \\
\hline 11년차 & 138.6 & 71.8 & 195,394 \\
\hline 12년차 & 140.0 & 72.5 & 197,444 \\
\hline
\end{tabular}

판매량은 증가하지 않는 것을 볼 수 있다(Table 8, 9, 10) 연결열부하 $140 \mathrm{Gcal} / \mathrm{h}$ 규모의 포화년도의 시간대별 $(8,760$ 시간) 난방수요 분석결과 동절기 12 월에 최대열부하가 발생 하였다(Fig. 3).

냉방 연결열부하 $112 \mathrm{Gcal} / \mathrm{h}$ 규모의 포화년도의 시간대별 냉방수요 분석결과 하절기인 6월 9월만 냉방수요가 발생하 였다(Fig. 4). 냉난방을 함께 분석한 결과 동절기는 난방부하 곡선과 유사하게 나타나는 반면, 하절기는 업무/공공용 냉방

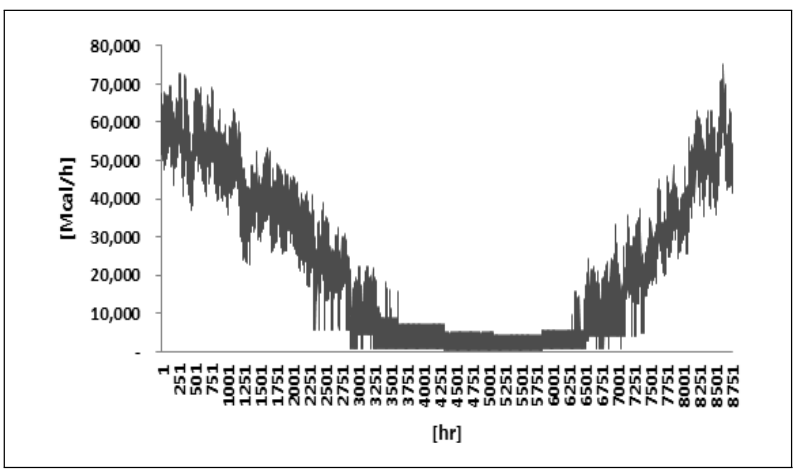

Fig. 3 Hourly Heating Load Pattern

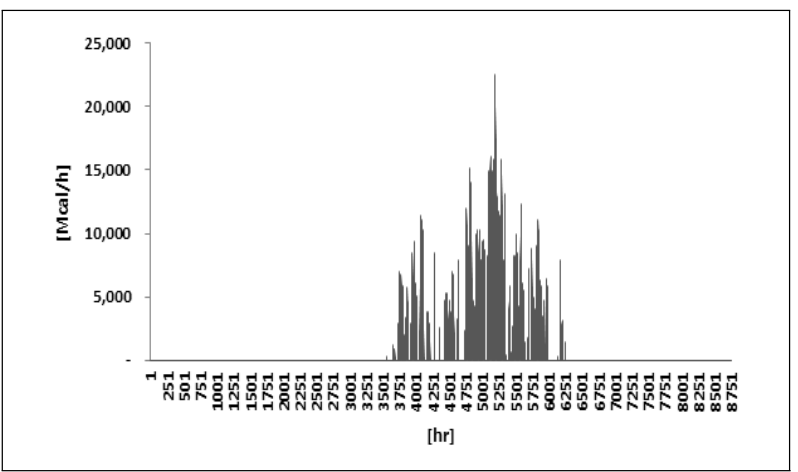

Fig. 4 Hourly Cooling Load Pattern

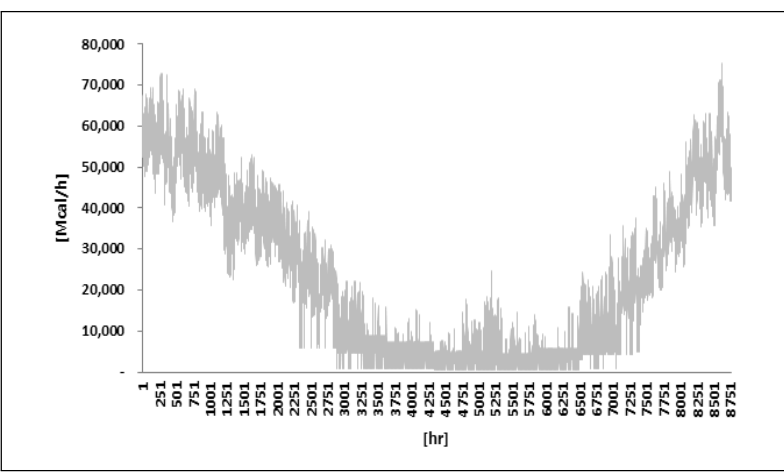

Fig. 5 Hourly Cooling and Heating Load Pattern 
부하로 인해 부하가 증가하는 것을 볼 수 있다(Fig. 5).

\section{2 생산 분석결과}

포화년도 기준 연간 전력생산량은 $60,707 \mathrm{MWh}$ 으로 산출되 었으며, 연간 열 생산량은 Case 1 의 경우 $141,034 \mathrm{Gcal} / \mathrm{y}$, Case 2 의 경우 $169,239 \mathrm{Gcal} / \mathrm{y}$, Case 3 의 경우 $197,444 \mathrm{Gcal} / \mathrm{y}$ 으 로 분석되었다(Table 11).

수요 $140 \mathrm{Gcal} / \mathrm{h}$ 를 기준으로 시간대별 열원별 생산 Pattern 을 분석결과 $\mathrm{CHP}$ 는 연중 가동되었으며, $\mathrm{PLBwg}$ 의 경우 동절 기에 가동이 되었다(Fig. 6).

\section{3 경제성 분석결과}

사업의 경제성 분석결과 바이오매스를 이용한 열병합발전

Table 11. Production Planning in Saturation Period

\begin{tabular}{c|c|c|c}
\hline \multicolumn{2}{c|}{ 구분 } & $\begin{array}{c}\text { 전력 생산 } \\
\text { MWh/y }\end{array}$ & $\begin{array}{c}\text { 열 생산 } \\
\text { Gcal/y }\end{array}$ \\
\hline \multirow{4}{*}{ Case 1 } & CHP & 60,707 & 129,758 \\
\cline { 2 - 4 } & PLBwg & & 10,000 \\
\cline { 2 - 4 } & 축열조 & & 1,276 \\
\cline { 2 - 4 } & 합계 & 60,707 & 141,034 \\
\hline \multirow{4}{*}{ Case 2 } & CHP & 60,707 & 142,740 \\
\cline { 2 - 4 } & PLBwg & & 24,057 \\
\cline { 2 - 4 } & 축열조 & & 2,441 \\
\cline { 2 - 4 } & 합계 & 60,707 & 169,239 \\
\hline \multirow{4}{*}{ Case 3 } & CHP & 60,707 & 152,482 \\
\cline { 2 - 4 } & PLBwg & & 43,088 \\
\cline { 2 - 4 } & 축열조 & & 1,873 \\
\cline { 2 - 4 } & 합계 & 60,707 & 197,444 \\
\hline
\end{tabular}

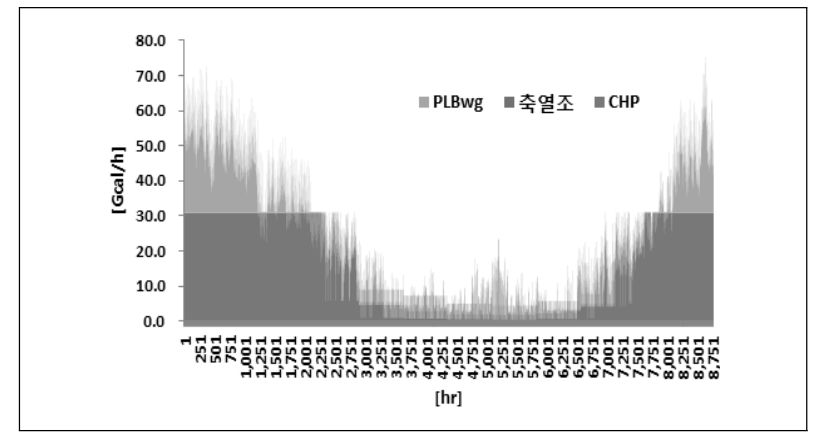

Fig. 6 Hourly Production Planning Pattern
사업의 경우 연결열부하 $100 \mathrm{Gcal} / \mathrm{h}$ 규모의 경우 IRR $4.6 \%$, $\mathrm{NPV}-24,183$ 백만원, 연결열부하 $120 \mathrm{Gcal} / \mathrm{h}$ 규모의 경우 IRR $6.2 \%, \mathrm{NPV}-15,572$ 백만원, 연결열부하 $140 \mathrm{Gcal} / \mathrm{h}$ 규 모의 경우 IRR $6.9 \%, \mathrm{NPV}-11,162$ 백만원으로 분석되었다 (Table 12).

\section{Table 12. Analysis Result of IRR}

\begin{tabular}{c|c|c|c}
\hline \multicolumn{2}{c|}{ 구분 } & IRR(\%) & NPV(백만원) \\
\hline \multirow{3}{*}{ Bio } & Case 1 & $4.6 \%$ & $-24,183$ \\
\cline { 2 - 4 } 연료 & Case 2 & $6.2 \%$ & $-15,572$ \\
\cline { 2 - 4 } & Case 3 & $6.9 \%$ & $-11,162$ \\
\hline
\end{tabular}

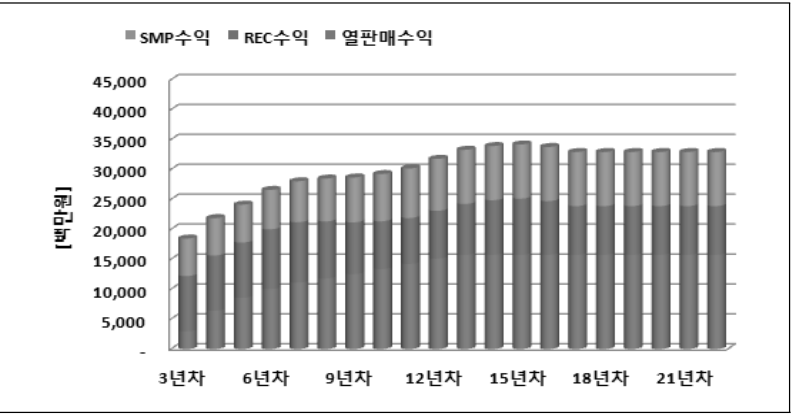

Fig. 7 Case 1 Sales Revenue by Year

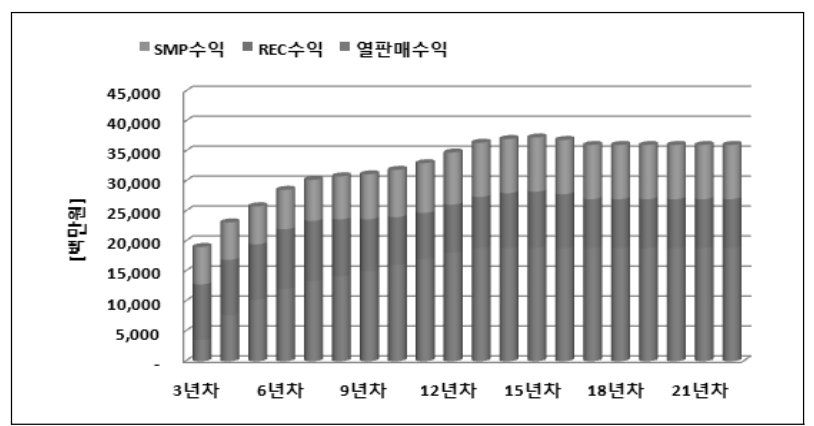

Fig. 8 Case 2 Sales Revenue by Year

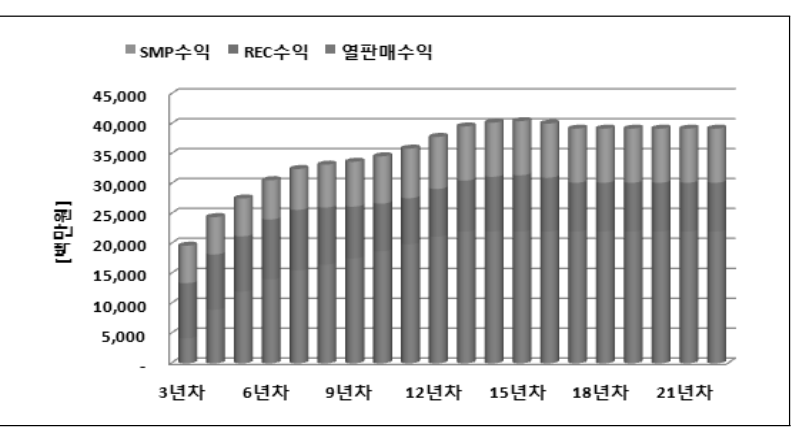

Fig. 9 Case 3 Sales Revenue by Year 


\section{논문 5}

Case별 균등한 비율로 사업규모를 증가 시킨 결과, Case 2 는 Case 1 대비 $1.6 \%$ 의 경제성 상승률을 보인 반면, 동등 비율로 규모를 확장시킨 Case 3은 Case 2 대비 $0.7 \%$ 의 경제 성 상승률을 보였다. 사업규모가 커질수록 열수익으로 인한 매출은 증가 하지만(Fig. 7, 8, 9), 연료비가 비싼 PLBwg 가 동량의 증가로 변동비가 증가하여 사업규모가 커질수록 경제 성의 상승폭은 오히려 줄어드는 것으로 나타났다(Fig. 10, 11, 12).

사업의 민감도를 분석하기 위하여 Case 3 을 기준으로 바 이오매스 연료가격, 열요금 단가, 투자비, REC 단가, SMP

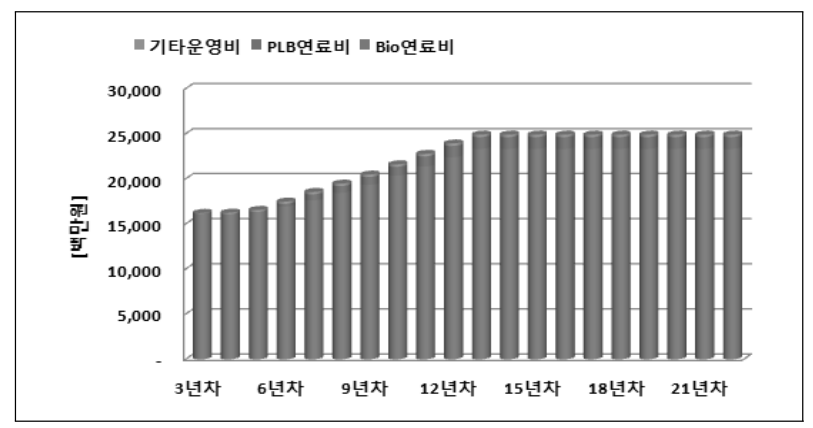

Fig. 10 Case 1 Variable Cost by Year

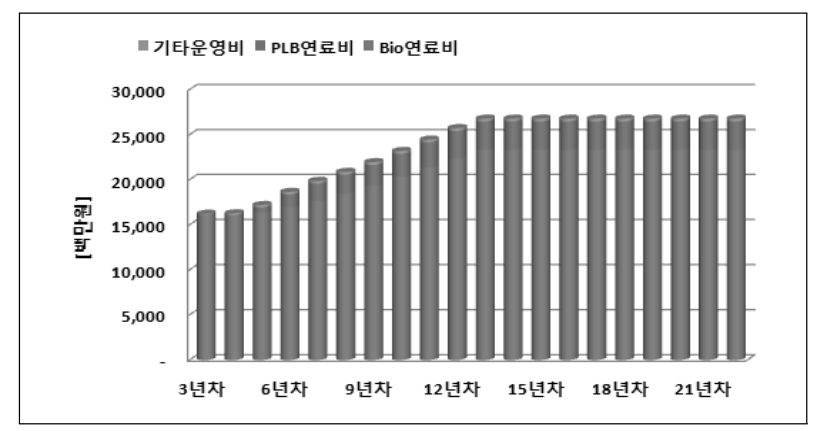

Fig. 11 Case 2 Variable Cost by Year

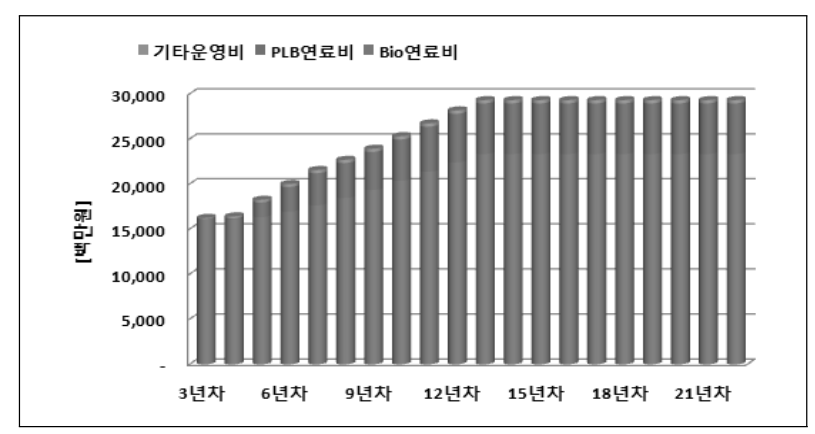

Fig. 12 Case 3 Variable Cost by Year
단가의 변화에 따른 민감도를 분석 한 결과, 바이오매스의 연 료가격이 사업에 가장 큰 영향을 미치는 것으로 분석되었고 이를 각각 Table 13과 Fig. 12에 도식하였다.

\section{4. 결 론}

본 연구에서는 신재생에너지중 전기와 대규모 열을 생산하 여 발전과 난방을 공급할 수 있는 바이오매스를 이용한 열병 합발전소의 사업 타당성을 연구하였다.

수요처 규모별 시나리오를 적용하여 사업 타당성을 분석한 결과 Case 1 (연결열부하 $100 \mathrm{Gcal} / \mathrm{h}$ )의 경우 IRR은 $4.6 \%$ 로 사업성이 없는 것으로 분석되었으며, Case 2, 3(연결열부하 $120 \mathrm{Gcal} / \mathrm{h} .140 \mathrm{Gcal} / \mathrm{h}$ )의 경우 각각 IRR $6.2 \%, 6.9 \%$ 로 시 중 금리 보다 높은 수익률을 도출하였다.

사업의 규모가 커질수록 PLBwg의 가동으로 수익성이 떨 어졌으며, $9.9 \mathrm{MW}$ 급 바이오매스 열병합발전 적정 사업규모 는 연결열부하기준 $100 \mathrm{Gcal} / \mathrm{h}$ 이상, $140 \mathrm{Gcal} / \mathrm{h}$ 이하로 분석 되었다.

\section{Table 13. Standard of Sensitivity Analysis}

\begin{tabular}{c|c|c|c}
\hline 구분 & Worst Case & Normal Case & Best Case \\
\hline 연료단가 & $+5 \%$ & $0 \%$ & $-5 \%$ \\
\hline 열요금단가 & $-5 \%$ & $0 \%$ & $+5 \%$ \\
\hline 투자비 & $+5 \%$ & $0 \%$ & $-5 \%$ \\
\hline REC단가 & $-5 \%$ & $0 \%$ & $+5 \%$ \\
\hline SMP단가 & $-5 \%$ & $0 \%$ & $+5 \%$ \\
\hline
\end{tabular}

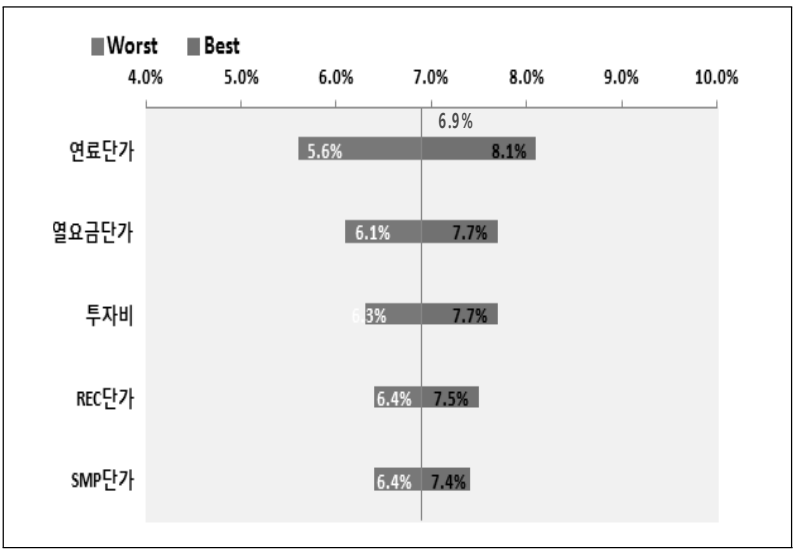

Fig. 13 Analysis Result of Sensitivity 
사업의 민감도를 분석한 결과 바이오매스의 연료가격이 가 장 큰 영향을 미치는 것으로 나타났으며, 연료가격이 $5 \%$ 상 승시 IRR이 $1.3 \%$ 하락하였고, $5 \%$ 하락시 IRR이 $1.2 \%$ 로 증가 하였다.

예측할 수 없는 화석연료의 가격 및 수급의 불안정과 높아 가는 환경규제정책에 대응하기 위해 신재생에너지를 이용한 사업의 중요성은 점점 커지고 있다. 그 중 전기와 열을 동시 에 생산할 수 있는 바이오매스를 이용한 열병합 발전사업이 점차 확대 될 것으로 예상된다. 이런 바이오매스를 이용한 사 업의 사업성을 확보하기 위해서는 열수요처에 맞는 적정규모 의 설비 설계 및 안정적인 연료수급을 통한 연료가격 변동성 을 줄여야 할 것이다.

\section{References}

[1] Korea Energy Economics Institute, 2011, A Study on the Plan for the Promotion of District Heating and Cooling using Renewable Energy.

[2] Korea Energy Management Corporation, 2013, Korea Energy Handbook 2013.

[3] Korea Energy Management Corporation, 2013, District Heat and Power Business Handbook 2013.

[4] Korea Energy Management Corporation, 2013, 2012 New\&Renewable Energy White Paper.

[5] Korea Energy Economics Institute, 2014, KEEI Monthly Energy Trends.

[6] Korea Energy Economics Institute, 2013, 2013 Yearbook of Energy Statistics.

[7] Korea Energy Economics Institute, 2010, A Study on the Optimization of District Heat and Power System.

[8] Korea Power Exchange. 2014, Market Report 2013.

[9] BP, 2014, 2014 Energy Outlook 2035.

[10] EIA, 2014, Annual Energy Outlook 2014 Early Release Overview.

\section{최 재 영}

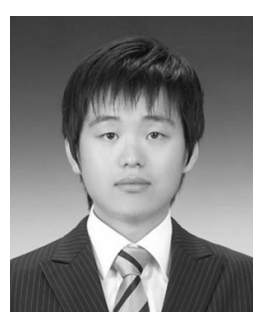

2010년 (주)GS파워 입사

2014년 연세대학교 에너지자원공학과 공학석사

현재 GS파워 영업전략팀 사원

(E-mail : chlwo083@hanmail.net)

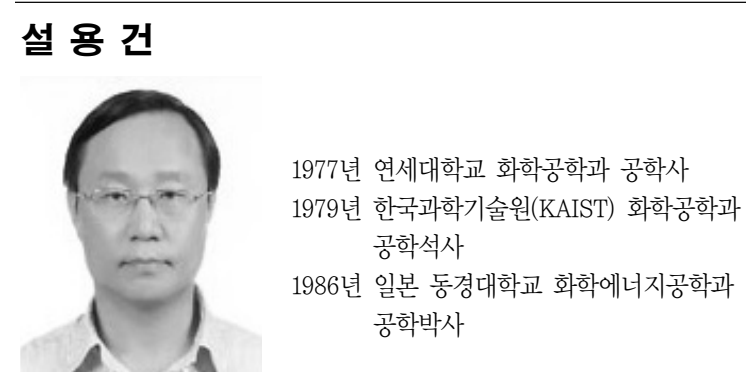

현재 연세대학교 화공생명공학과 교수

(E-mail : shulyg@yonsei.ac.kr) 